\title{
A comparative assessment of antiproliferative properties of resveratrol and ethanol leaf extract of Anogeissus leiocarpus (DC) Guill and Perr against HepG2 hepatocarcinoma cells
}

Jeremiah Olorunjuwon Olugbamii ${ }^{1,2,3}$, Robert Damoiseaux ${ }^{4,5}$, Bryan France ${ }^{4}$, Esther Modupe Onibiyo ${ }^{6}$, Michael Adedapo Gbadegesin', Shivani Sharma ${ }^{3}$, James Kazimierz Gimzewski ${ }^{2,3,7}$ and Oyeronke Adunni Odunola ${ }^{1 *}$

\begin{abstract}
Background: Epidemiological and experimental evidences have shown cancer as a leading cause of death worldwide. Although the folklore use of plants as a reliable source of health-restoring principles is well-documented, the search for more of such plants that are active against diseases, such as cancer, continues. We report here a laboratory-based evidence of the relevance of an ethanol leaf extract of Anogeissus leiocarpus (A2L) in comparison with resveratrol, a natural polyphenol, in cancer therapy.

Methods: The quantitative assessment of flavonoid and phenolic contents involved quercetin and gallic acid as standards, respectively were determined using spectrophotometry. Cytotoxicity was determined fluorometrically using propidium-iodide-staining method. Antioxidant status, adenosine triphosphate (ATP) levels, caspase activities and mitochondrial integrity were assessed using fluorometry/luminometry.

Results: The antioxidant assay demonstrated that A2L possesses a strong antioxidant capacity as compared with the reference compounds, ascorbic acid and butylated hydroxytoluene. This is further buttressed by the significantly high level of phenolics obtained in the quantitative assessment of the extract. A 72-h post-treatment examination indicated that both A2L and resveratrol modulate the proliferation of HepG2 liver carcinoma cells in a time- and concentrationdependent manner. Determination of the total nuclei area, propidium-iodide negative and positive nuclei areas all further buttress the modulation of cell proliferation by $\mathrm{A} 2 \mathrm{~L}$ and resveratrol with the indication that the observed cell death is due to apoptosis and necrosis at lower and higher concentrations of treatments respectively. At lower concentrations (0.39-3. $13 \mu \mathrm{g} / \mathrm{mL}$ ), resveratrol possesses higher tendencies to activate caspases 3 and 7. Bioenergetically, both resveratrol and A2L do not adversely affect the cells at lower concentrations $(0.39-6.25 \mu \mathrm{g} / \mathrm{mL}$ for resveratrol and $12.5-100.0 \mu \mathrm{g} / \mathrm{mL}$ for A2L) except at higher concentrations $(12.5-25.0 \mu \mathrm{g} / \mathrm{mL}$ for resveratrol and $200-800 \mu \mathrm{g} / \mathrm{mL}$ for $\mathrm{A} 2 \mathrm{~L}$ ) which are more pronounced in A2L-treated cells. Furthermore, the antioxidant status of HepG2 cells is not perturbed by resveratrol as compared with A2L. Assessment of 24-h post-treatment mitochondrial function shows that resveratrol is not mitotoxic as compared with $\mathrm{A} 2 \mathrm{~L}$ which exhibits mitotoxicity at its highest concentration. (Continued on next page)
\end{abstract}

\footnotetext{
* Correspondence: ronodunola@yahoo.com

1 Department of Biochemistry, Cancer Research and Molecular Biology

(CRMB) Laboratories, University of Ibadan, Ibadan, Oyo, Nigeria

Full list of author information is available at the end of the article
} 
(Continued from previous page)

Conclusions: Taken together, findings from this study showed that $\mathrm{A} 2 \mathrm{~L}$ possesses strong antiproliferative activity and its prospect in the management of hepatocellular carcinoma deserves further investigation.

Keywords: Free radicals, Resveratrol, Anogeissus leiocarpus, HepG2 cells, Cell death, Cell proliferation, Morphological changes

\section{Background}

The current statistics reveal that cancer is now a leading cause of death worldwide, and liver cancer is one of the deadliest forms. Liver cancer has been reported to be the second most common cause of death from cancer globally after lung cancer [1]. Increasingly new cases of liver cancer were diagnosed, from 626,162 in 2002 to 782,451 in 2012. This figure is projected to increase to $1,341,344$ cases by 2035 [1].

There has been an increased search for anticancer medicinal plant products based on the fact that surgical and traditional therapeutic approaches (chemotherapy and radiation) are, at present, unable to control most cancer types [2]. Furthermore, considering the concomitant toxic effects associated with the use of synthetic chemicals in cancer therapy, scientific research efforts are being geared toward naturally-occurring plant sources which are therapeutically effective, culturally acceptable and economically accessible [3].

Anogeissus leiocarpus (DC) Guill and Perr (English/ common name: Axlewood tree; Yoruba name: Ayin) is one of the medicinal plants contained in the Nigeria's diverse flora (Dalziel, 1937). It has varied applications in Nigerian traditional medicine mostly in the treatment of respiratory diseases, ascaricide, gonorrhoea, general body pain, blood clots. [4]. The result of an oral acute toxicity study revealed no death with doses up to $3200 \mathrm{mg} / \mathrm{kg}$ body weight in an animal model. Furthermore, histopathological lesions were not observed in all the organs except the lungs, which showed congestion, oedema and bronchitis. These results suggested that the leaf extract of $A$. leiocarpus could be used with some degree of safety especially by oral route [5].

Resveratrol (3,5,4'-Trihydroxystilbene) is a natural polyphenol which was isolated from the root of Veratrum grandiflorum by Takaoka with its chemical structure characterised in 1940 [6]. Studies have shown that resveratrol can exert antitumour effects at the stages of cancer initiation, promotion and progression [7]. Moreover, resveratrol has also received considerable attention due to its potential chemopreventive and chemotherapeutic properties [8]. This study, therefore, evaluated the in vitro cell modulatory properties of ethanol leaf extract of $A$. leiocarpus (A2L) as compared with resveratrol in HepG2 liver carcinoma cell line.

\section{Methods \\ Collection of leaves of $A$. leiocarpus and preparation of its ethanol extract}

A. leiocarpus leaves were collected from Lokoja, Nigeria and authenticated at the Department of Botany, University of Ibadan with the reference number: UIH 22402. The sample leaves were washed with distilled water $\left(\mathrm{dH}_{2} \mathrm{O}\right)$ to remove any contaminants, air-dried under shade until it attained a constant weight, grinded to powder, sieved, packed into polythene bags and stored at $4{ }^{\circ} \mathrm{C}$. Four hundred grams $(400 \mathrm{~g})$ of the powered plant part was macerated in $70 \%$ ethanol $(1600 \mathrm{~mL})$ for $72 \mathrm{~h}$ with intermittent stirring/shaking [9]. At the end of the extraction, the extract was filtered using Whatman filter paper No.1 (Whatman Ltd., England) to remove all unextractable matters, including cellular materials and other constituents that are insoluble in the extraction solvent. The filtrate was concentrated using a rotary evaporator (RE-52A, Shanghai Ya Rong Biochemistry Instrument Factory, Shanghai) under reduced pressure (in order to speed up the process) at $40{ }^{\circ} \mathrm{C}$ and stored at $4{ }^{\circ} \mathrm{C}$ until when needed. The percentage yield of the extraction was $14.17 \% \mathrm{w} / \mathrm{w}$.

\section{Determination of total phenolic content}

The amount of total phenolics in the plant extract was determined with the Folin-Ciocalteau reagent using the method of Spanos and Wrolstad [10] with some modifications an in Olugbami et al. [11]. Briefly, $2.5 \mathrm{~mL}$ of $1 /$ 10 dilution of Folin-Ciocalteau's reagent and $2 \mathrm{~mL}$ of $\mathrm{Na}_{2} \mathrm{CO}_{3}(7.5 \% \mathrm{w} / \mathrm{v})$ were added to $0.50 \mathrm{~mL}$ of the extract $(800 \mu \mathrm{g} / \mathrm{mL})$ and incubated at $45{ }^{\circ} \mathrm{C}$ for 15 mins. The absorbance of was measured at $765 \mathrm{~nm}$ using UV/VIS spectrometer T70. Results are expressed as micrograms of gallic acid equivalents per milligram of dry weight ( $\mu \mathrm{g}$ $\mathrm{GAE} / \mathrm{mg}$ ) of extract.

\section{Determination of total flavonoid content}

This was carried out by using the method described by Nickavar and colleagues [12]. Briefly, $2.5 \mathrm{~mL}$ of the extract $(800 \mu \mathrm{g} / \mathrm{mL})$ was mixed with $2.5 \mathrm{~mL} \mathrm{AlCl}_{3}$ reagent in $90 \%$ ethanol and allowed to stand for 40 mins at room temperature. After that, the absorbance of the mixture was measured at $415 \mathrm{~nm}$ using UV/VIS spectrometer T70. The blank was made up of $2.5 \mathrm{~mL}$ of $90 \%$ ethanol plus sample solution $(2.5 \mathrm{~mL})$. The TFC which is 
expressed as micrograms of quercetin equivalents per milligram $(\mu \mathrm{g} \mathrm{QE} / \mathrm{mg}$ ) of extract was determined on the basis of the linear calibration curve of quercetin (absorbance versus quercetin concentration).

\section{Cell line and reagents}

HepG2 (human liver carcinoma) cell line used in this study was generously provided by Dr. Samuel French (Dept. of Pathology and Laboratory Medicine, University of California, Los Angeles, CA, USA). The cells were grown in Dulbecco's Modified Eagle's Medium [DMEM] (Sigma-Aldrich, MO, USA) supplemented with 10\% ( $v /$ v) fetal bovine serum (Sigma Aldrich, MO, USA), 1\% Lglutamine (Sigma Aldrich, MO, USA) and 1\% penicillin/ streptomycin (Sigma Aldrich, MO, USA). The cells were cultured in a water-jacketed incubator (Forma Scientific, $\mathrm{MO}, \mathrm{USA}$ ) at $37{ }^{\circ} \mathrm{C}, 5 \% \mathrm{CO}_{2}, 95 \%$ air with the renewal of medium being every 2-3 days. Resveratrol, dimethyl sulphoxide (DMSO), 0.05\% trypsin, 0.4\% trypan blue, and propidium iodide (PI) were purchased from Sigma Aldrich, MO, USA. Hoechst 33,342 was from Invitrogen, USA while GSH/GSSG-Glo ${ }^{\text {tm }}$, Caspase-Glo 3/7, and Mitochondrial ToxGlo ${ }^{\mathrm{Tm}}$ Assay reagents were obtained from Promega Corporation, WI, USA.

\section{Cell counting, image acquisition and analysis}

Cells were harvested and re-suspended in medium to ensure a single cell suspension and then counted on a haemocytometer based on trypan blue dye exclusion method ( $0.4 \%$ trypan blue; Sigma-Aldrich, St Louis, MO) by adding $10 \mu \mathrm{L}$ of trypan blue solution to $10 \mu \mathrm{L}$ of cell suspension $(1: 1 \quad v / v)$. ImageXpress ${ }^{\circ}$ Micro Widefield High Content Screening System and its associated MetaXpress $^{\bullet}$ High Content Image Acquisition and Analysis Software interface were utilised for image acquisition and analysis. After dye addition and incubation $(1 \mathrm{~h})$, images were captured with two software predetermined excitation/emission filter sets; 380/535 nm for Hoechst and 555/645 $\mathrm{nm}$ for PI. Transmitted light and fluorescence images from each well were acquired using a $20 \times$ and $4 \times$ dry objective lenses respectively. Under these settings and by plating HepG2 cells at the predetermined optimum cell densities indicated above, the system was able to capture from $\sim 100$ to 400 cells per well and the images were subsequently analysed using the MetaXpress ${ }^{\circ}$ Analysis Software. To define nuclei as individual units or regions of interest (ROIs), preprocessing filters and intensity thresholds were applied for image segmentation. Segmented images were subjected to data classification by the use of the MetaXpress $^{\oplus}$ Analysis Software. The percentage of dead cells was calculated from the total number of ROIs per well. Cell nuclei emitting fluorescence signal from both Hoechst and PI (fluorescence co-localisation) were considered as dead cells, while cells emitting only Hoechst signal were counted as live cells.

\section{Cytotoxicity determination}

Resveratrol (100 mg) was prepared as $20 \mathrm{mg} / \mathrm{mL}$ by adding $5 \mathrm{~mL}$ of $100 \%$ DMSO and then sonicated to ensure total dissolution of the solute. While the extract was prepared in $0.5 \%$ DMSO, sonicated and centrifuged at $13500 \mathrm{rpm}$ with the supernatant preserved for subsequent use. For the assays, resveratrol and extract were further diluted to appropriate concentrations in complete medium. In both cases, the final DMSO concentration did not exceed $0.25 \%$. Having obtained an optimum DMSO concentration and cell density, cells were prepared and then treated with resveratrol $(0.39,0.78,1.56,3.13,6.25,12.5$, and $25 \mu \mathrm{g} / \mathrm{mL})$ and A2L $(12.5,25,50,100,200,400$, and $800 \mu \mathrm{g} / \mathrm{mL}$ ). The treated cells were incubated for $72 \mathrm{~h}$ with the effects of treatment being monitored at 24 h-intervals. At each interval, the plates were stained and then imaged with an ImageXpress MicroXL high-content fluorescence microscope.

\section{Mitochondrial toxicity testing}

The Mitochondrial ToxGlo ${ }^{\text {TM }}$ Assay used here is a cell-based assay that employs multiplexed chemistry for predicting potential mitochondrial dysfunction as a result of xenobiotic exposure. The assay is based on the differential measurement of biomarkers associated with changes in cell membrane integrity and cellular ATP levels relative to vehicle-treated control cells. Ten microlitres $(10 \mu \mathrm{L})$ of culture medium containing approximately 1500 cells is plated on opaque-walled, black tissue culture plates compatible with fluorescent and luminescent measurements (clear bottoms). Being attachment-dependent, cells were incubated for $24 \mathrm{~h}$ to adhere to the substrate of the plate. The cells were then treated with $10 \mu \mathrm{L}$ of sample and incubated for $24 \mathrm{~h}$. Using an electronic multichannel pipette, $5 \mu \mathrm{L}$ of 5X Cytotoxicity Reagent was dispensed to each well of the plate and mixed briefly $(1 \mathrm{~min})$ by orbital shaking (1300 rpm) to ensure Reagent/sample homogeneity and to mitigate possible Reagent/sample partitioning. The plate was then incubated at $37^{\circ} \mathrm{C}$ for 30 mins and fluorescence was measured with rhodamine 110 filter set at $485 \mathrm{~nm}_{\mathrm{Ex}} / 525 \mathrm{~nm}_{\mathrm{Em}}$ using Flexstation 3 microplate reader (Molecular Devices, Sunnyvale, CA). Thereafter, the assay plate was equilibrated to room temperature $(10$ mins $)$ and $25 \mu \mathrm{L}$ of ATP Detection Reagent was added to each well. The plate was mixed by orbital shaking (1300 rpm) for 3 mins and luminescence was measured by using Wallac microplate reader. 


\section{Caspase 3/7-activity}

Caspase 3/7-activity was assessed with Caspase-Glo 3/7 luminescent Assay reagents. Cells were plated at 1500 per well in a volume of $12.5 \mu \mathrm{L}$ culture medium in white 384-multiwell plates and allowed to attach for $24 \mathrm{~h}$. After treatments (vehicle or test substances) in a volume of $12.5 \mu \mathrm{L}$ culture medium, plates were subsequently incubated for $24 \mathrm{~h}$. Then $25 \mu \mathrm{L}$ of Caspase-Glo 3/7 Reagent was added to each well containing $25 \mu \mathrm{L}$ of blank, negative control cells or treated cells in culture medium. Contents of wells were mixed using a plate shaker at $1300-1500 \mathrm{rpm}$ for $30 \mathrm{~s}$ and the plates were incubated at room temperature for $1 \mathrm{~h}$ before measuring luminescence on Analyst GT multimode reader (Molecular Devices Corporation, Sunnyvale, CA, USA).

\section{Determination of adenosine triphosphate (ATP) levels}

ATP levels were measured using CellTiter-Glo Luminescent Cell Viability Assay. Cells were plated at 3000 per well in triplicate in white 384-multiwell plates and allowed to attach for $24 \mathrm{~h}$. After treatments (vehicle or test substances) in a volume of $12.5 \mu \mathrm{L}$ culture medium, the plates were subsequently incubated for $24 \mathrm{~h}$ and then a volume of CellTiter-Glo reagent equal to the content of each well was added. After 10 mins, luminescence was read using Wallac plate reader (Perkin-Elmer, USA), and signal intensity was calculated relative to inplate DMSO control wells.

\section{Determination of glutathione levels (antioxidant status)}

Reduced-oxidised glutathione levels were determined by using the luminescence-based GSH/GSSG-Glo ${ }^{\mathrm{Tm}}$ Assay reagents. Cells were plated at 3000 per well in a volume of $25 \mu \mathrm{L}$ culture medium in white 384-multiwell plates and allowed to attach for $24 \mathrm{~h}$. After treatments (vehicle or test substances) in a volume of $25 \mu \mathrm{L}$ culture medium, plates were subsequently incubated for $24 \mathrm{~h}$, cell culture medium/treatment was removed and plates were treated according to manufacturer's instructions to determine the levels of total and oxidised glutathione. After 15 mins of incubation to stabilise the signal, luminescence was read using Wallac plate reader (Perkin-Elmer, USA). GSH/GSSG ratios are calculated directly from relative luminescent unit (RLU) measurements.

\section{Statistical analysis}

For statistical analysis, data were analysed using SigmaPlot 11.0 and GraphPad Prism 5. The results were expressed as mean $\pm \mathrm{SD}$ (standard deviation) and the median inhibitory/cytotoxic concentration $\left(\mathrm{I} / \mathrm{CC}_{50}\right)$ values were obtained from the linear regression plots. One-way analysis of variance (ANOVA) was used to assess differences between means (student's $t$ test, where applicable); if significant differences were found $(p<0.05,0.01$, or 0.001$)$, Tukey-Kramer multiple comparison test was considered for post-test.

\section{Results \\ Quantitative phytochemical analysis shows the significantly higher content of phenolics than flavonoids in $\mathrm{A} 2 \mathrm{~L}$}

A comparison of the total phenolic and flavonoid contents based on gallic acid and quercetin as the standard compounds, respectively indicates that A2L is highly rich in phenolic contents $(605.6075 \pm 0.6182 \mu \mathrm{g}$ GAE/ mg extract) as compared with its flavonoid contents (119.4792 $\pm 3.1302 \mu \mathrm{g}$ QE/mg extract).

\section{Resveratrol displays mitogenic activity while A2L shows antiproliferative activity}

Assessment of the proliferative activities of resveratrol and A2L in HepG2 cells for $72 \mathrm{~h}$ shows, on one hand, that resveratrol is mitogenic at lower concentrations throughout the period of treatment. On the other hand, A2L is consistent in its antiproliferative activity. For both resveratrol and A2L, cell proliferation seems not remarkably affected at $24 \mathrm{~h}$ after treatment. Overall, both resveratrol and A2L are antiproliferative at high concentrations being more pronounced with A2L which significantly $(p<0.05 ; 0.01$; 0.001 ) displays a time- and dose-dependent antiproliferative activity. As expected, the negative control (DMSOtreated cells) maintained a similar proliferation pattern at the various concentrations within the same time of exposure (Fig. 1).

Resveratrol and A2L could not induce the death of HepG2 cells at lower concentrations

Assessment of percentage dead cell based on the number of cells that are positive for propidium iodide indicates that resveratrol and A2L could not significantly $(p>0.05)$ induce HepG2 cell death at lower concentrations for the $72 \mathrm{~h}$ of exposure. One sharp difference that can be noticed is that A2L shows higher tendencies to be death-inducing in a time-dependent manner than resveratrol. At the highest concentration, A2L maintains a significantly $(p<0.001)$ strong death-inducing ability from $24 \mathrm{~h}$ through $72 \mathrm{~h}$ of exposure (Fig. 2).

Total, positive, and negative nuclear sizes are affected in a time- and concentration-dependent manner

The total nuclear area (Fig. 3) which indicates the overall combination of the area occupied by the genetic materials of both dead and live cells, followed the same trend with cell count (Fig. 1). In the case of the negative nuclei total area, a parameter that measures the genetic/nuclear size of live cells, it shows no changes at lower concentrations but a significant $(p<0.01)$ increase at higher 


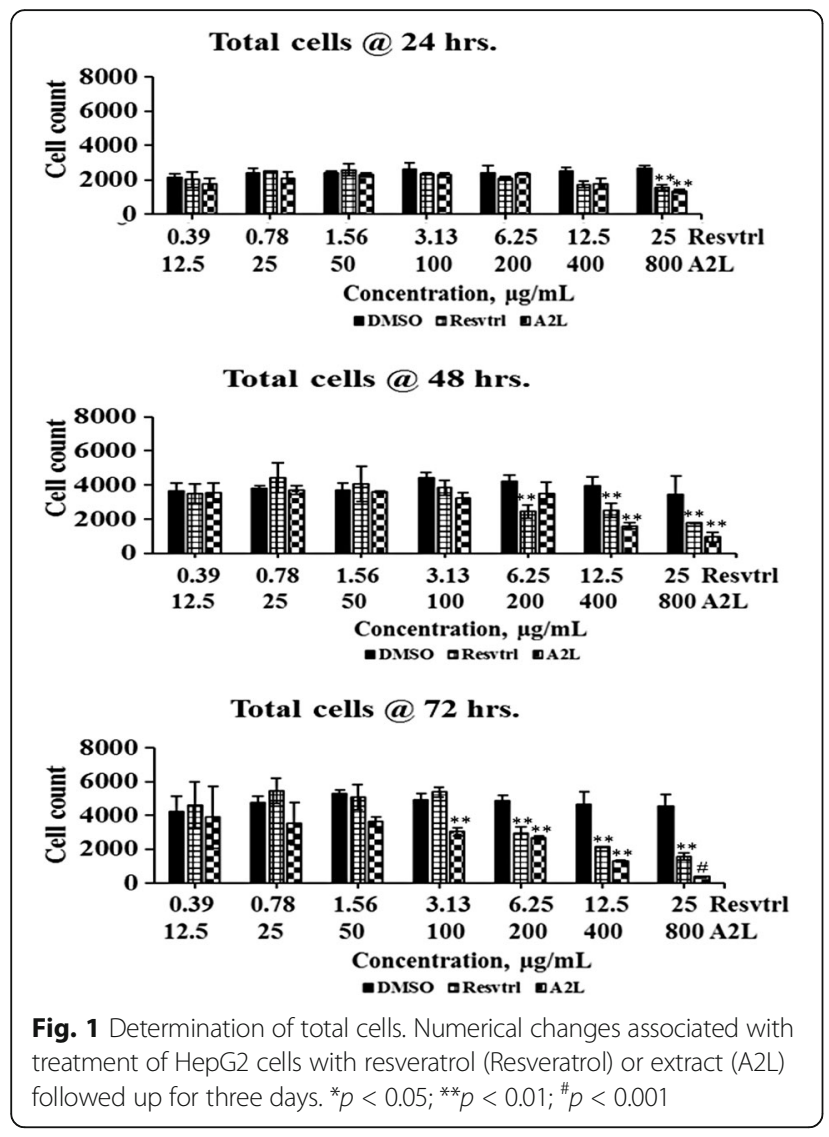

concentrations most especially at $72 \mathrm{~h}$ post-treatment (Fig. 4). Lastly, the positive nuclei total area, which indicates the nuclear/genetic size of dead cells, shows a gradual increase in a time- and dose-dependent manner (Fig. 5).

\section{Both resveratrol and $\mathrm{A} 2 \mathrm{~L}$ do not possess mitotoxic} potential

Assessment of the influence of both resveratrol and A2L on possible mitotoxicity shows that both are unable to induce a depletion in the levels of ATP across the various concentrations of treatment considered in this study. The only exception being A2L which significantly depleted the ATP levels at its highest concentration (Fig. 6).

HepG2 cell death induced by both resveratrol and A2L involves the activation of executioner caspases

Across the various concentrations of treatment, resveratrol and $\mathrm{A} 2 \mathrm{~L}$ demonstrated the induction of the apoptosis-inducing caspases 3 and 7. For both treatments, activation of these caspases are more pronounced at the lower concentrations compare to the higher concentrations. As the concentrations increase, resveratrol shows a more drastic reduction in the levels of these

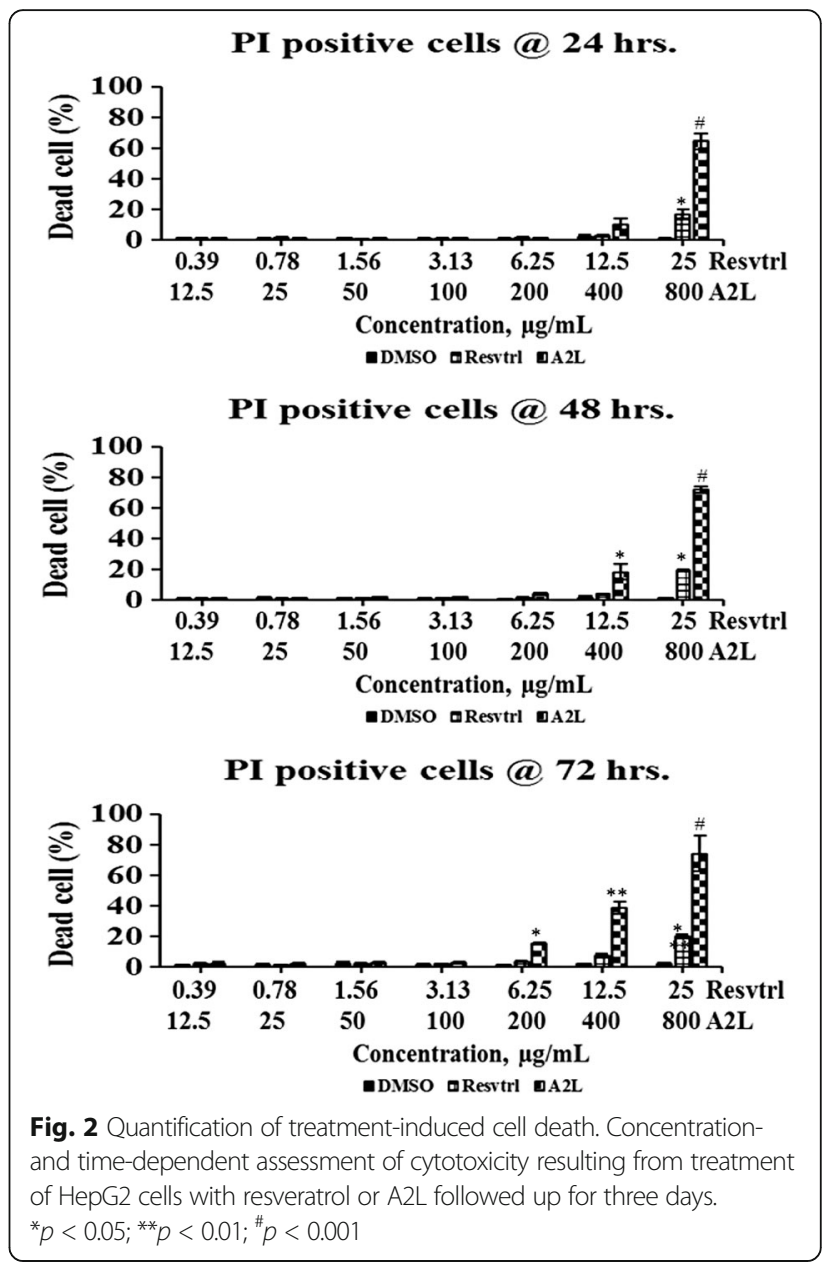

caspases as compared with the minimal change recorded for A2L (Fig. 7).

\section{Depletion in ATP levels seems to account principally for} the cell death induced by $\mathrm{A} 2 \mathrm{~L}$

Both resveratrol and A2L could not significantly $(p>0.05)$ affect the ATP levels at lower concentrations, but A2L significantly $(p<0.05)$ exhibited ATP-depletion capacity at higher concentrations (Fig. 8).

\section{Resveratrol and $\mathrm{A} 2 \mathrm{~L}$ are antioxidant boosters for} HepG2 cells

The antioxidant status of HepG2 cells was unaffected significantly $(P>0.05)$ by resveratrol and A2L as compared with the negative control. The only exception being that A2L demonstrated higher reducing potential than resveratrol throughout all the concentrations of treatment ultimately culminating in a significant $(p<0.01)$ decrease in the antioxidant status at the highest concentration of A2L (Fig. 9). 


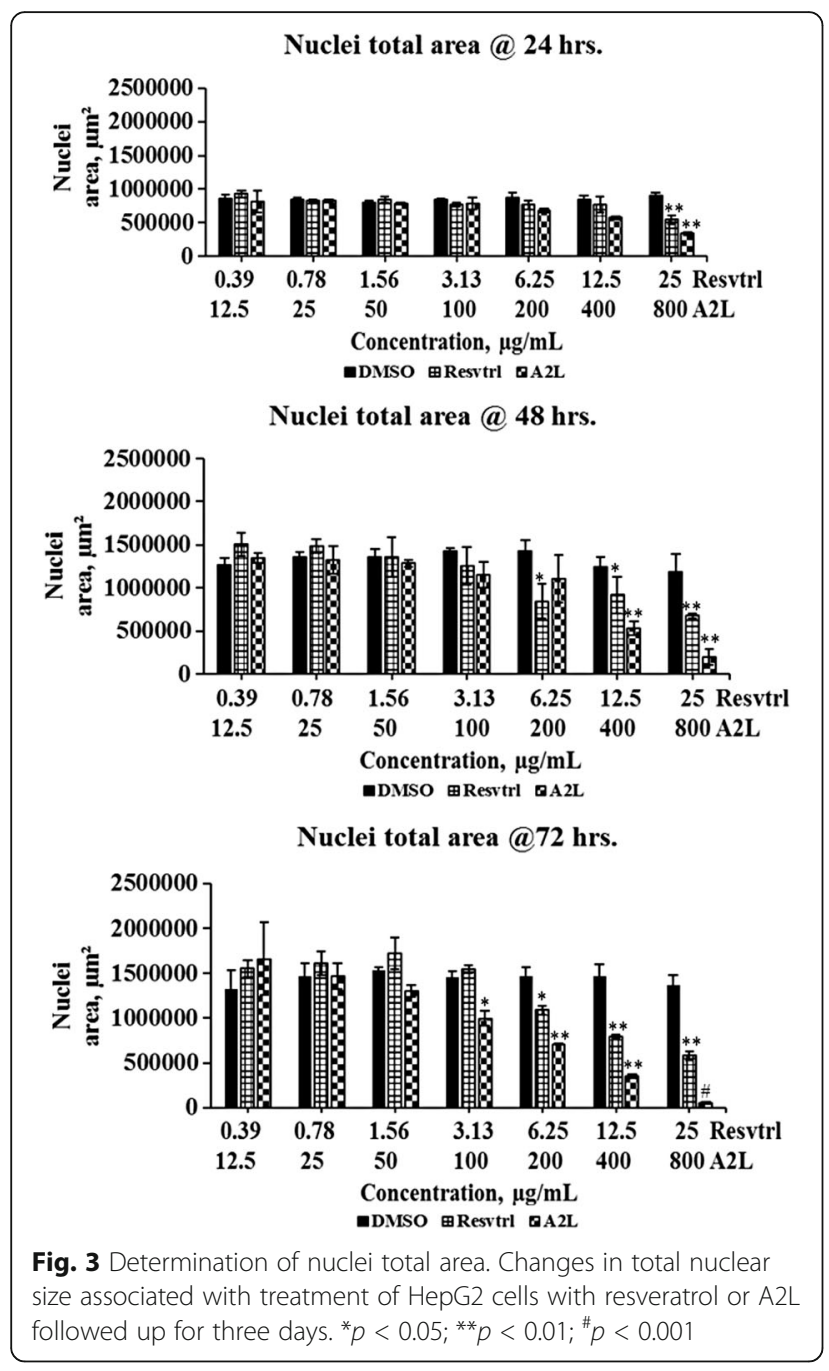

Resveratrol and $\mathrm{A} 2 \mathrm{~L}$ induced morphological changes in HepG2 cells

Morphological assessment of HepG2 cells shows a more pronounced effect induced on the cells by A2L most especially at its highest concentration as compared with resveratrol (Figs. 10 and 11).

\section{Discussion}

The high morbidity and mortality rates associated with hepatocellular carcinoma (HCC) has been attributed principally to its chemoresistance with proven resistance to chemotherapeutic agents, such as adriamycin (ADM), cisplatin, 5-fluorouracil (5-FU) and doxorubicin [13, 14]. It is known that HCC is a major public health problem in many parts of the world, with high incident areas in East Asia and sub-Saharan Africa [15]. Our efforts in this work were channeled towards application of a plantderived natural product in the management of HCC.

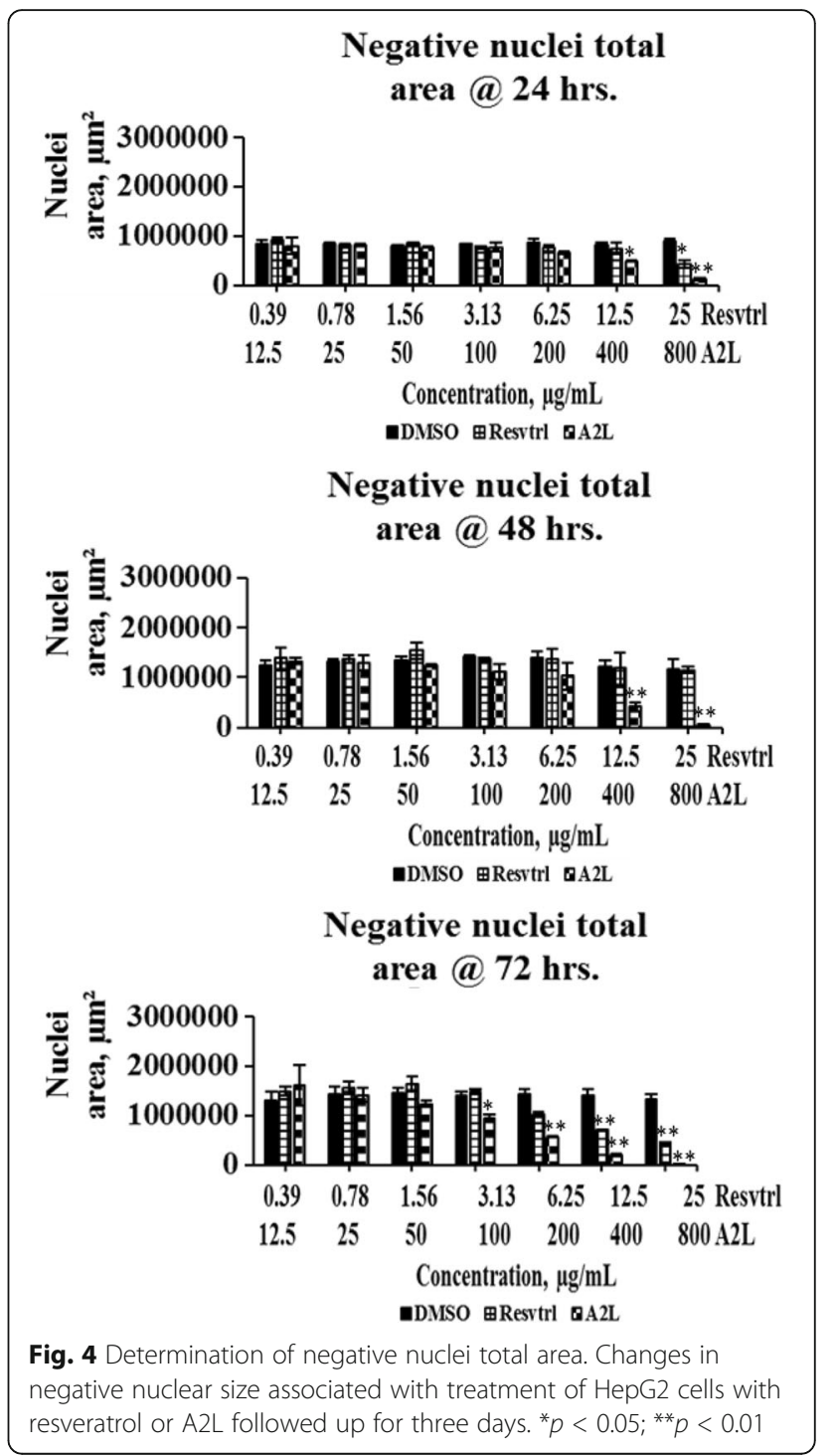

Various reports have shown that free radicals/reactive oxygen species (ROS), such as nitric oxide, hydroxyl radical, superoxide anion, are generated from both endogenous and exogenous sources. These products are generally reactive with cellular macromolecules, such as lipids, proteins, deoxyribonucleic acid (DNA), resulting in lipid peroxidation, degradation/denaturation of proteins, oxidation of DNA, respectively. These are the molecular basis of many diseases including cancer such as $\operatorname{HCC}[16,17]$. Findings from the present study demonstrated that the extract $(\mathrm{A} 2 \mathrm{~L})$ used in this work possesses a very strong free radical scavenging activity as compared with ascorbic acid, the reference compound. This observed activity of A2L may be due to its high total phenolic content demonstrated in the quantitative phytochemical analysis. Undoubtedly, the flavonoid 


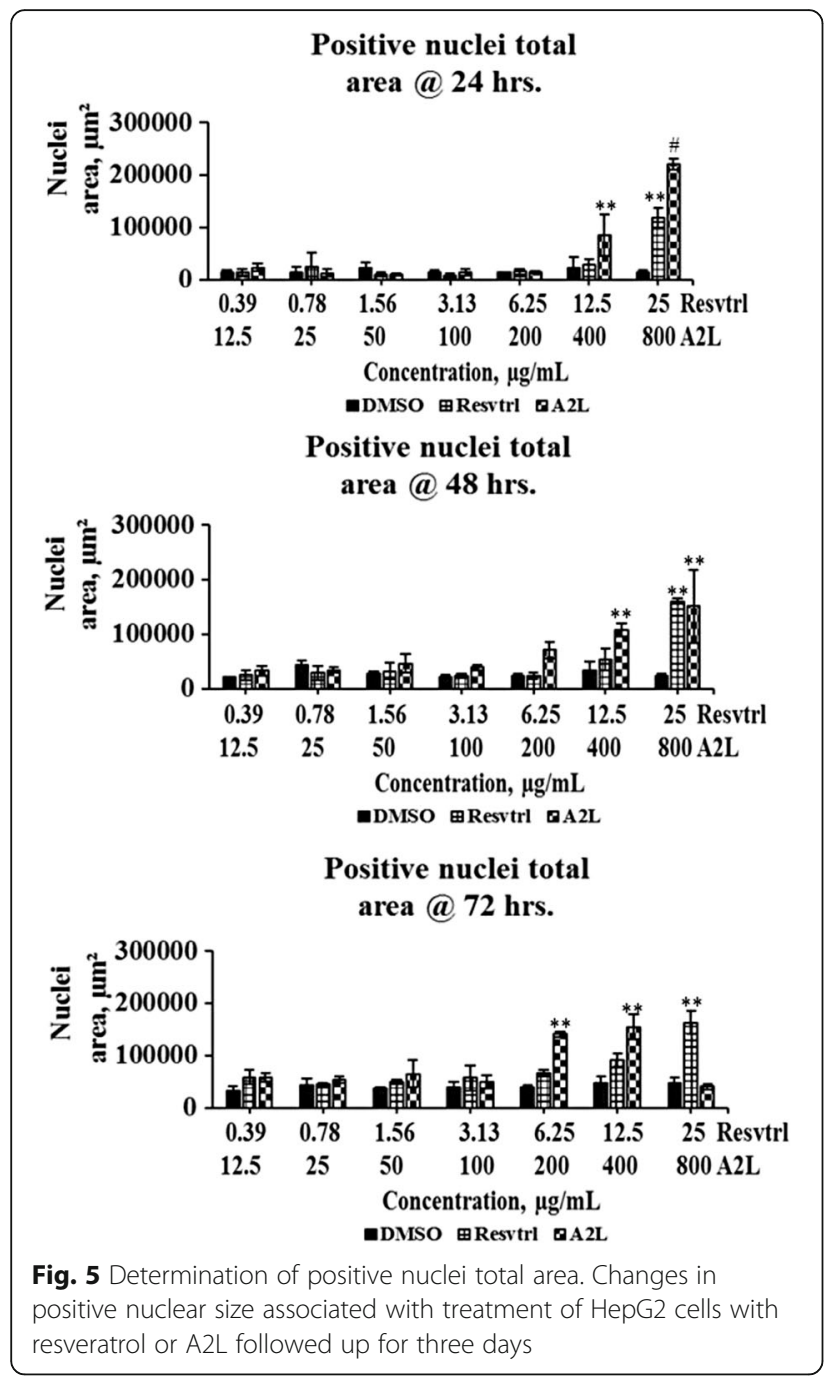

content, although quite minimal, may also be a contributing factor. Plant phenolics and flavonoids have been reported to exhibit efficient radical scavenging, metal chelating and antioxidant activities $[18,19]$.

The antiproliferative activity of resveratrol in HepG2 cells has been previously reported and here we confirm the same order except that its lower concentrations displayed mitogenic tendencies throughout the $72 \mathrm{~h}$ of exposure to treatment. In like manner, A2L almost demonstrated the same trend as resveratrol except that it exhibited greater antiproliferative activity in a time- and concentration-dependent manner $[20,21]$. The values obtained for total nuclear, positive nuclear, and negative nuclear areas all corroborated the antiproliferative, apoptotic and necrotic effects of treatments depending on the concentrations of either resveratrol or A2L. Antiproliferative activity is indicated by the decrease in total and negative nuclei areas, while the increase in positive nuclei area implies necrotic cell-death [22-24].

In order to gain insights into the antiproliferative activities of both resveratrol and A2L, we assessed mitochondrial function and found that ATP synthesis was not significantly $(p>0.05)$ affected most especially at the lower concentrations, but became pronounced at higher concentrations. This is in line with a previous study [25]. Previous reports have indicated that resveratrol can induce mitochondrial biogenesis in HepG2 cells and may clearly explain the results we obtained in this present study $[26,27]$. Although, this activity seems to be concentrationdependent as, at higher concentrations, both resveratrol and A2L were able to significantly $(p<0.05)$ reduce the ATP levels with A2L being potent $(p<0.01)$. The resultant effect of this disruption in ATP levels is the cell death induced at these concentrations.

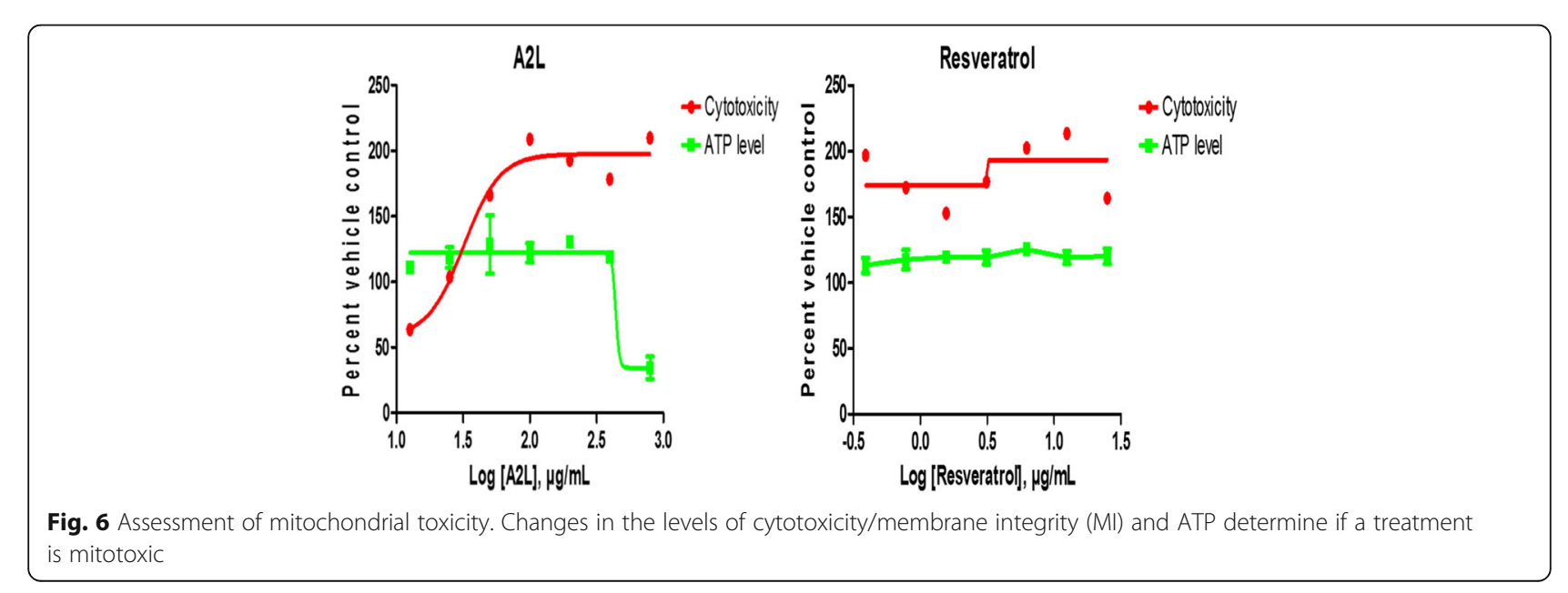




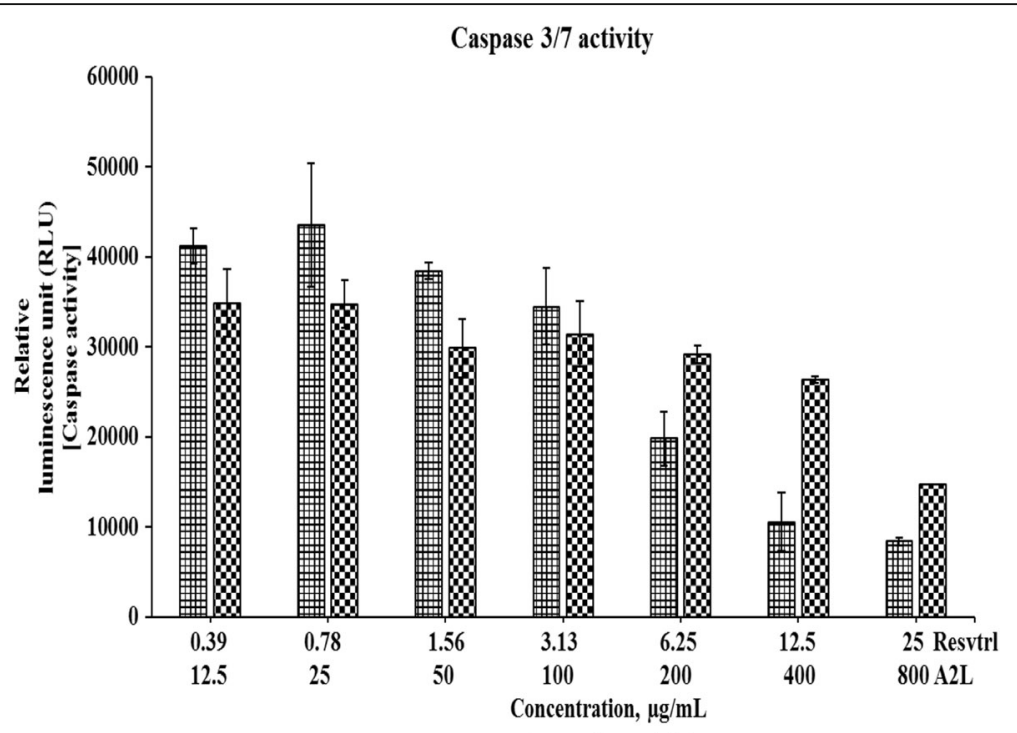

田Resvtrl. 0 A2L

Fig. 7 Caspase activation levels. This shows the trend of caspase activities induced by treatment with either resveratrol or A2L

In accordance with earlier reports, we observed that resveratrol maintained the antioxidant status of HepG2 cells throughout the concentrations considered in this study. This activity has been reported to be due to the capability of resveratrol to induce an increase in the activities of catalase (CAT), superoxide dismutase (SOD), GSH peroxidase (GPx), NADPH quinone oxidoreductase, and GSH-S-transferase with an attendant increase in intracellular glutathione (GSH) level [28, 29]. Results recorded on A2L indicated that the extract induced similar effect with resveratrol on the antioxidant status of HepG2 cells, with the exception of the highest concentration in which the extract significantly depleted the antioxidant level of the cells.

Resveratrol has been noted to induce apoptosis in cancer cells as it has been demonstrated in this study by the upregulation of the activities of effector caspases-3 and -7. For resveratrol-treated HepG2 cells, the trend of caspase activities obtained here across the various concentrations implies that the level of apoptotic cell death attained a threshold point after which other forms of cell death, most probably necrosis, becomes predominant. This point is evident from the decline in caspase activity. As for the A2L-treated cells, apoptotic level seems to have been well-maintained except at the highest concentration in which there was a remarkable reduction in the caspase activities $[8,30]$.

\section{Conclusion}

Our findings validated the antiproliferative activities of resveratrol in HepG2 hepatocellular carcinoma cells. Here, for the first time we have been able to

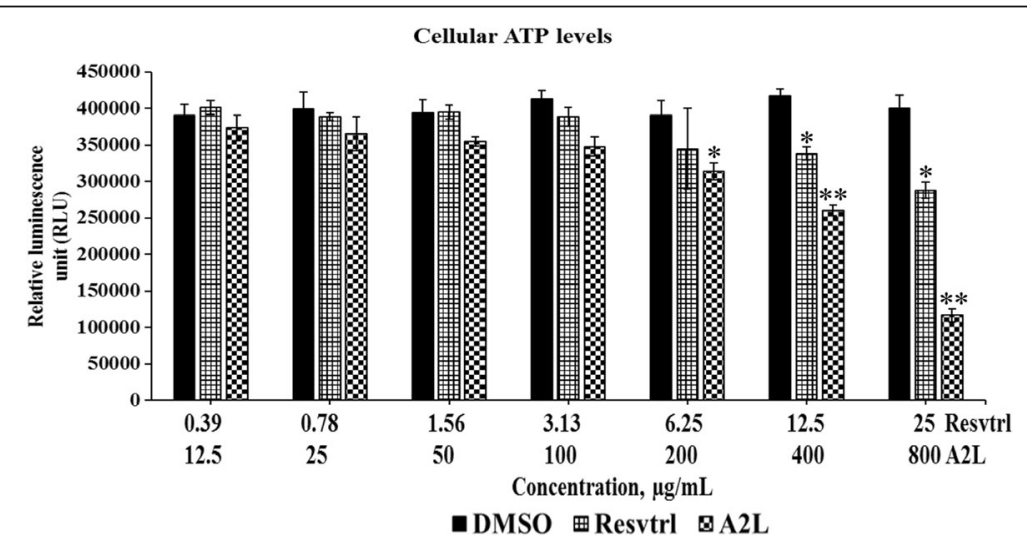

Fig. 8 Effects of treatment on ATP levels. Variations in ATP status of HepG2 cells treated with resveratrol or A2L. ${ }^{*} p<0.05 ;{ }^{* *} p<0.01$ 


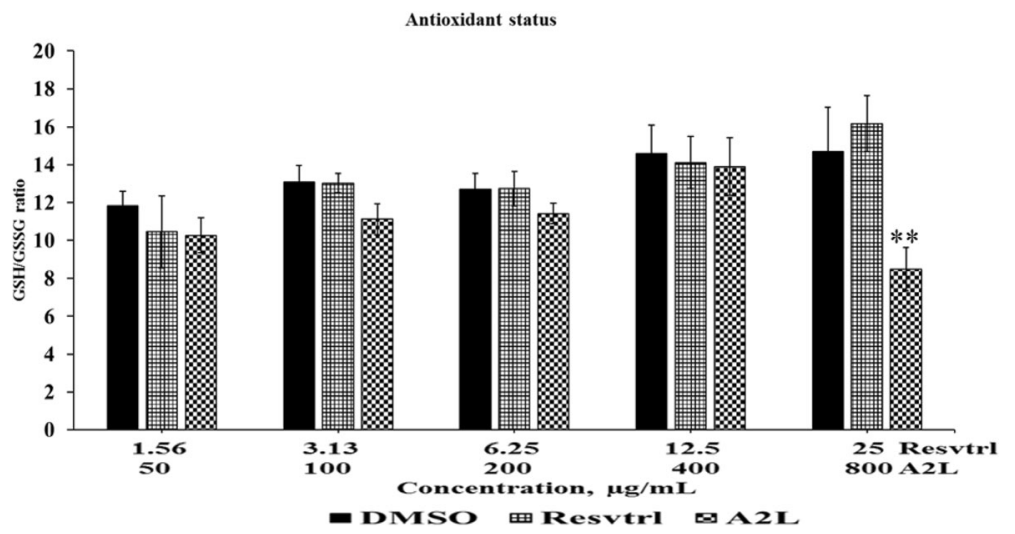

Fig. 9 Effects of treatment on anti-oxidant status. Anti-oxidant status (GSH/GSSG ratio) of HepG2 cells treated with resveratrol or A2L. ${ }^{* *} p<0.01$
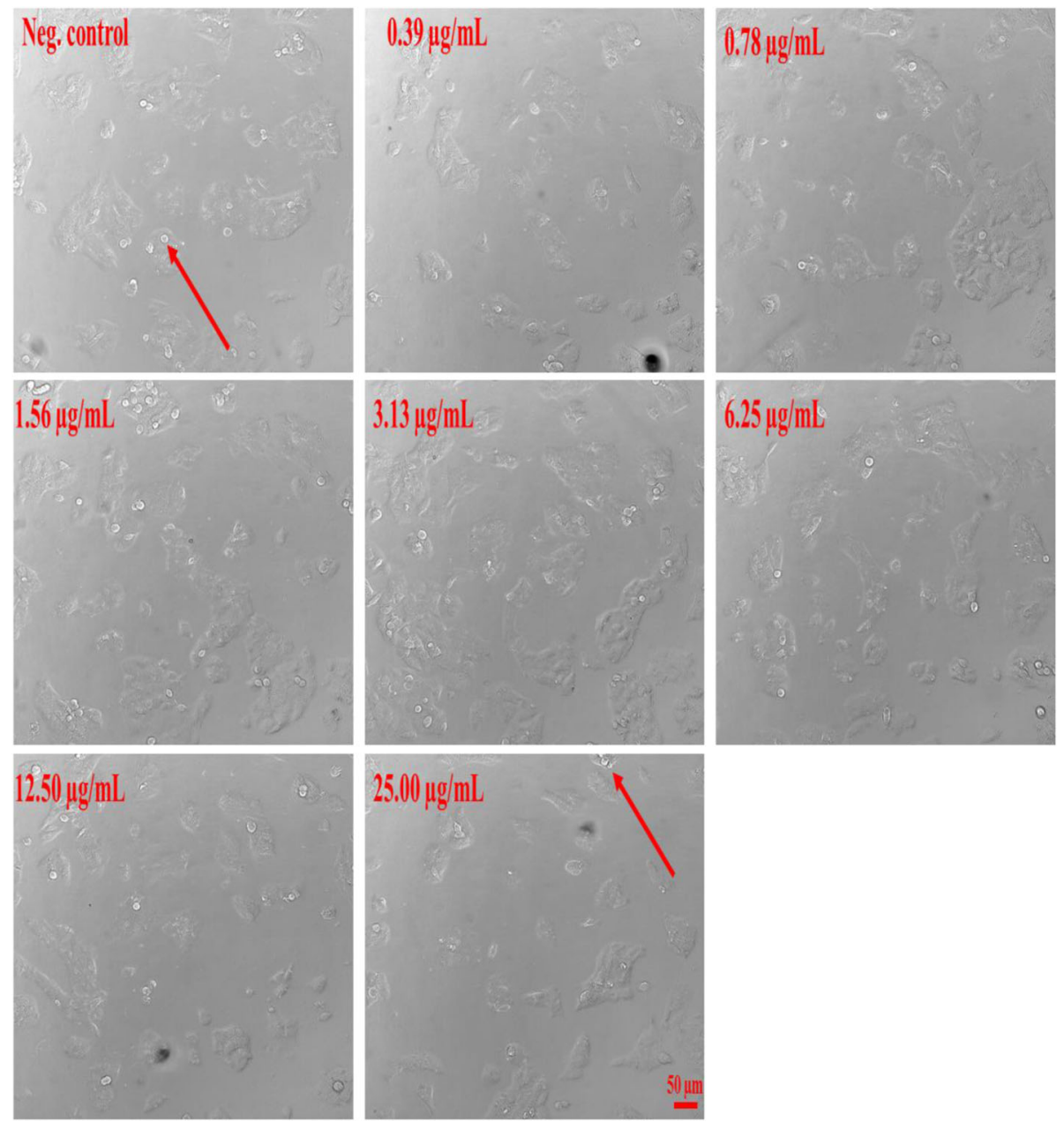

Fig. 10 Changes in cellular morphology as recorded using a widefield fluorescent microscopy. Resveratrol-induced morphological changes in HepG2 cells after $24 \mathrm{~h}$ of treatment $(\times 20)$ 

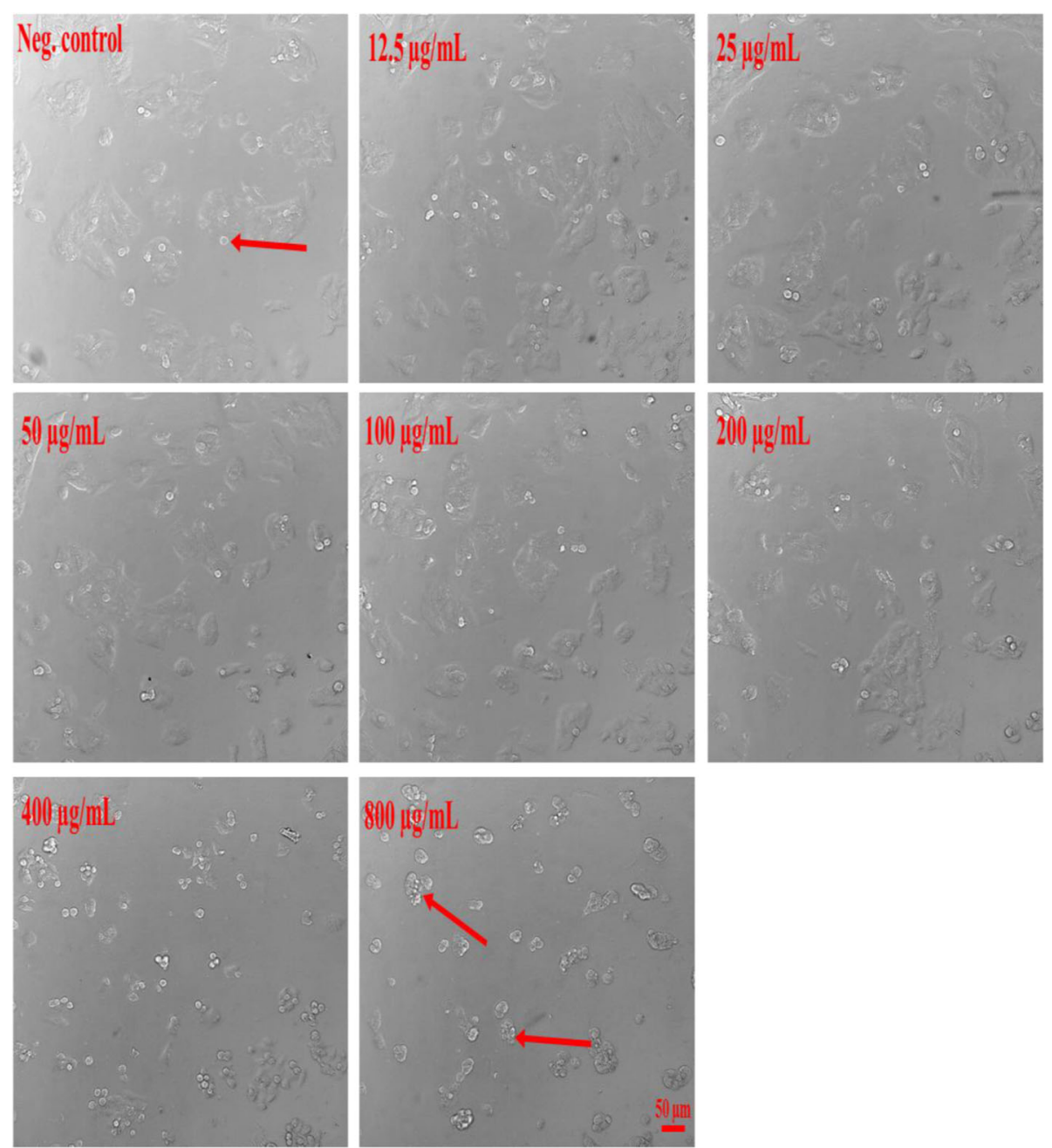

Fig. 11 Changes in HepG2 cell morphology as recorded using a widefield fluorescent microscopy. A2L-induced morphological changes in HepG2 cells after $24 \mathrm{~h}$ of treatment $(\times 20)$

demonstrate the significant time- and concentrationdependent antiproliferative capability of the ethanol leaf extract of A. leiocarpus (A2L). However, both resveratrol and the extract are non-cytotoxic except at high concentrations in which $\mathrm{A} 2 \mathrm{~L}$ is significantly more cytotoxic on HepG2 liver cancer cells than resveratrol in a time-dependent manner. Mechanisms of cell death by both treatments seem not to be ATPor antioxidant-depletion dependent.

\section{Abbreviations}

A2L: ethanol leaf extract of Anogeissus leiocarpus;: ATP: adenosine triphosphate; CAT: catalase; DMEM: Dulbecco's Modified Eagle's Medium; DMSO: dimethyl sulphoxide; DNA: deoxyribonucleic acid; GAE: gallic acid equivalents; GPx: glutathione peroxidase.; GSH: reduced glutathione; HCC: hepatocellular carcinoma; $1 / \mathrm{CC}_{50}$ : median inhibitory/cytotoxic concentration; QE: quercetin equivalents; ROS: reactive oxygen species; SD: standard deviation; SOD: superoxide dismutase

\section{Acknowledgments}

The authors thank Drs. Ekambaram Ganapathy and Samuel French of the Department of Pathology and Laboratory Medicine, UCLA, for the kind gift of HepG2 cells. Alicia Brotchie of Corning Incorporated and Heather Bartz of Promega Corp. are kindly appreciated for the research materials they generously made available. The authors acknowledge the use of AFM at the Nano and Pico Characterisation Core Facility, CNSI, UCLA.

\section{Funding}

JOO received support from the US Department of State's Bureau of Educational and Cultural Affairs (Foreign Fulbright Commission) through the Institute of International Education (IIE). This work was also supported by a Johnsson Cancer Comprehensive Centre (JCCC) grant received by JKG.

\section{Availability of data and materials}

All data supporting the study are presented in the manuscript or available upon request from Jeremiah Olorunjuwon Olugbami, Ph.D. (olugbamijuwon@yahoo.com).

\section{Authors' contributions}

JOO: Study design, performed the experiments, acquisition and analysis of data, and drafted the manuscript. RD: Study design, supervised the study 
design, acquisition and analysis of data. BF: Involved in the acquisition and analysis of data. EMO: Involved in the preliminary aspect of the experiments. MAG: Supervised the study design and drafted the manuscript. SS: Study design and supervision. JKG: Study design and supervision. OAO: Study design, supervised the study design and drafted the manuscript.

\section{Ethics approval and consent to participate}

Intensive trainings by UCLA office of Environment, Health and Safety (EHS) and immunisation were undertaken before access was granted to carry out this study. No human subject was used.

\section{Consent for publication}

Not applicable.

\section{Competing interests}

The authors declare that they have no competing interests.

\section{Publisher's Note}

Springer Nature remains neutral with regard to jurisdictional claims in published maps and institutional affiliations.

\section{Author details \\ 'Department of Biochemistry, Cancer Research and Molecular Biology (CRMB) Laboratories, University of Ibadan, Ibadan, Oyo, Nigeria. ${ }^{2}$ Department of Chemistry and Biochemistry, University of California, Los Angeles, California, USA. ${ }^{3} \mathrm{Nano}$ and Pico Characterisation (NPC) Core Facility, California NanoSystems Institute (CNSI), University of California, Los Angeles, California, USA. ${ }^{4}$ Molecular Screening and Shared Resources (MSSR) Core Facility, California NanoSystems Institute (CNSI), University of California, Los Angeles, California, USA. ${ }^{5}$ Department of Molecular and Medicinal Pharmacology, University of California, Los Angeles, California, USA. ${ }^{6}$ Department of Chemical Sciences, Ajayi Crowther University, Oyo, Oyo, Nigeria. ${ }^{7}$ International Center for Materials Nanoarchitectonics Satellite (MANA), National Institute for Materials Science (NIMS), Tsukuba, Japan.}

Received: 13 February 2017 Accepted: 7 July 2017

\section{Published online: 02 August 2017}

\section{References}

1. Ferlay J, Soerjomataram II, Dikshit R, Eser S, Mathers C, Rebelo M, Parkin DM, Forman DD, bray F. cancer incidence and mortality worldwide: sources, methods and major patterns in GLOBOCAN 2012. Int J Cancer. 2015;136:E359-86.

2. Kalimuthu S, Se-Kwon K. Cell survival and apoptosis signaling as therapeutic target for cancer: marine bioactive compounds. Int J Mol Sci. 2013;14:2334-54.

3. Farombi EO, Adepoju BF, Ola-Davies OE, Emerole GO. Chemoprevention of aflatoxin $\mathrm{B}_{1}$-induced genotoxicity and hepatic oxidative damage in rats by kolaviron, a natural bioflavonoid of Garcinia kola seeds. Eur J Cancer Prev. 2005;14:207-14.

4. Mann A, Amupitan JO, Oyewale AO, Okogun JI, Ibrahim K. An ethnobotanical survey of indigenous flora for treating tuberculosis and other respiratory diseases in Niger state, Nigeria. J Phytomedicine Ther. 2007;12:1-21.

5. Agaie BM, Onyeyili PA, Muhammad BY, Ladan MJ. Acute toxicity effects of the aqueous leaf extract of Anogeissus leiocarpus in rats. African J Biotechnol. 2007;6(7):886-9

6. Takaoka MJ. Of the phenolic substances of white hellebore (Veratrum grandiflorum Loes. Fil.). J Fac Sci Hokkaido Imp Univ. 1940;3:1-16.

7. Hsieh TC, Wu JM. Differential effects on growth, cell cycle arrest, and induction of apoptosis by resveratrol in human prostate cancer cell lines. Exp Cell Res. 1999;249(1):109-15.

8. Ou X, Chen Y, Cheng X, Zhang X, He Q. Potentiation of resveratrol-induced apoptosis by matrine in human hepatoma HepG2 cells. Oncol Rep. 2014;32(6):2803-9.

9. Olugbami JO, Gbadegesin MA, Odunola OA. In vitro evaluation of the antioxidant potential, phenolic and flavonoid contents of the stem bark ethanol extract of Anogeissus leiocarpus. Afr J Med Med Sci. 2014;43(Suppl 1):101-9.

10. Spanos GA, Wrolstad RE. Influence of processing and storage on the phenolic composition of Thompson seedless grape juice. J Agric Food Chem. 1990;38(7):1565-71.
11. Olugbami JO, Gbadegesin MA, Odunola OA. In vitro free radical scavenging and antioxidant properties of ethanol extract of Terminalia glaucescens. Pharm Res. 2015;7(1):49-56.

12. Nickavar B, Kamalinejad M, Mohandesi S. Comparison of the components of the essential oils from leaves and fruits of Grammosciadium platycarpum. Chem Nat Compd. 2006:42:686-8.

13. Elkholi IE, Hazem NM, ElKashef WF, Sobh MA, Shaalan D, Sobh M, El-Sherbiny IM. Evaluation of anti-cancer potential of capsaicin-loaded trimethyl chitosan-based nanoparticles in HepG2 hepatocarcinoma cells. J Nanomedicine Nanotechnol. 2014;5(6):1-8.

14. Li L, Wei XH, Pan YP, Li HC, Yang H, He QH, Pang Y, Shan Y, Xiong FX, Shao GZ, Zhou RL. LAPTM4B: a novel cancer-associated gene motivates multidrug resistance through efflux and activating PI3K/AKT signaling. Oncogene. 2010;29(43):5785-95.

15. Parkin DM. Global cancer statistics in the year 2000. Lancet Oncol. 2001;2(9):533-43.

16. Ortega AL, Mena S, Estrela JM. Glutathione in cancer cell death. Cancers (Basel). 2011;3(1):1285-310

17. Halliwell B. Oxidative stress, nutrition and health. Experimental strategies for optimization of nutritional antioxidant intake in humans. Free Radic Res. 1996;25(1):57-74.

18. Lim YY, Lim T, Tee JJ. Antioxidant properties of several tropical fruits: a comparative study. Food Chem. 2007;103(3):1003-8.

19. Dorman HJD, Koşar M, Kahlos K, Holm Y, Hiltunen R. Antioxidant properties and composition of aqueous extracts from Mentha species, hybrids, varieties, and cultivars. J Agric Food Chem. 2003;51(16):4563-9.

20. Notas G, Nifli A-P, Kampa M, Vercauteren J, Kouroumalis E, Castanas E. Resveratrol exerts its antiproliferative effect on HepG2 hepatocellular carcinoma cells, by inducing cell cycle arrest, and NOS activation. Biochim Biophys Acta. 2006;1760(11):1657-66.

21. Yu H, Li D, Zhang H, Xue H, Pan C, Zhao S, Wang L. Resveratrol inhibits invasion and metastasis of hepatocellular carcinoma cells. J Anim Vet Adv. 2010;9(24):3117-24.

22. Stervbo U, Vang O, Bonnesen C. Time- and concentration-dependent effects of resveratrol in HL-60 and HepG2 cells. Cell Prolif. 2006;39(6):479-93.

23. Zhu Y, Huang H, Wu Y. Anticancer and apoptotic activities of oleanolic acid are mediated through cell cycle arrest and disruption of mitochondrial membrane potential in HepG2 human hepatocellular carcinoma cells. Mol Med Rep. 2015;12(4):5012-8.

24. Olugbami JO, Damoiseaux R, France B, Gbadegesin MA, Stieg AZ, Sharma S, Odunola OA, Gimzewski JK. Atomic force microscopy correlates antimetastatic potentials of HepG2 cell line with its redox/energy status, and effects of curcumin and Khaya senegalensis. J Integr Med. 2017:15(3):214-30

25. Gallis JL, Serhan N, Gin H, Couzigou P, Beauvieux MC. Resveratrol plus ethanol counteract the ethanol-induced impairment of energy metabolism: 31P NMR study of ATP and sn-glycerol-3-phosphate on isolated and perfused rat liver. Pharm Res. 2012;65(3):387-95.

26. Kim S-K, Joe Y, Zheng M, Kim HJ, Yu J-K, Cho GJ, Chang KC, Kim HK, Han J, Ryter SW, Chung HT. Resveratrol induces hepatic mitochondrial biogenesis through the sequential activation of nitric oxide and carbon monoxide production. Antioxid Redox Signal. 2014;20(16):2589-605.

27. Baur JA, Pearson KJ, Price NL, Jamieson HA, Lerin C, Kalra A, Prabhu W, Allard JS, Lopez-Lluch G, Lewis K, Pistell PJ, Poosala S, Becker KG, Boss O, Gwinn D, Wang M, Ramaswamy S, Fishbein KW, Spencer RG, Lakatta EG, Le Couteur D, Shaw RJ, Navas P, Puigserver P, Ingram DK, de Cabo R, Sinclair DA. Resveratrol improves health and survival of mice on a high-calorie diet. Nature. 2006;444(7117):337-42.

28. Nah H, Lee W, Joo Y, Kim H, Choi S, Rew J, Kim SJ, Jung YD, Ahn BW, Park JS. Resveratrol protects HepG2 and chang liver cells from oxidative stress. Chonnam Med J. 2005:41:243-52.

29. Faghihzadeh F, Hekmatdoost A, Adibi P. Resveratrol and liver: a systematic review. J Res Med Sci. 2015;20(8):797-810.

30. Kai L, Samuel SK, Levenson AS. Resveratrol enhances p53 acetylation and apoptosis in prostate cancer by inhibiting MTA1/NuRD complex. Int J Cancer. 2010;126(7):1538-48. 